\title{
Os desafios de compreender o trabalho informal
}

\author{
EDUARDO DALBOSCO * \\ MÁRCIA DE MELO MARTINS KUYUMJIAN **
}

\section{Introdução}

O debate teórico sobre as diferenciações produtivas que ocorrem no mundo econômico, tendo-se como referencial o marco regulatório representado pelo estamento estatal, vem acumulando importantes contribuições para a discussão do trabalho, tanto como categoria econômica ligada à produção de valores, como participação do ser humano em um determinada historicidade, ao mesmo tempo determinador e determinado por texturas institucionais que fomentam e caracterizam o modo de ser do período.

Desde os anos 70, momento em que se inicia a decomposição das conquistas dos "trinta gloriosos anos" do pós-guerra, acompanhamos a proliferação de interpretações críticas acerca do desenvolvimento da produção e suas interrelações com o mercado de trabalho. Análises duais, que dividiam automaticamente as diferenças económicas em atrasadas e adiantadas, são superadas por uma análise de mérito sobre as transformações produtivas. O estudo desta dinâmica intersticial oportuniza uma abordagem sistêmica que compreende cada fenómeno a partir de sua relação com seu contexto.

* Formado em Filosofia e Especialista em Sociologia Urbana; Mestrando em Política Social, Departamento de Serviço Social da UnB.

** Professora do Departamento de Serviço Social da UnB e orientadora da pesquisa de mestrado de Eduardo Dalbosco.

${ }^{1}$ Revista Ser Social, no 5, Jul./Dez. 1999 
O trabalho humano, como fator de produção, como mecanismo de participação social ou força volitiva criadora do sujeito, é tratado como manifestação de uma realidade capitalista, uma relação social onde o poder é representado pela capacidade de acumulação e, consequentemente por um movimento incessante de criação, ampliação, crescimento e diversificação dos ramos de produção. Como síntese, temos uma divisão social do trabalho hegemonizada pelos setores mais dinâmicos e mais competitivos. Mais extensa e profunda será esta divisão quanto mais desenvolvida for a sociedade (Holzmann: 1997,64).

Cacciamali (1983, p. 13) reitera este processo, afirmando:

A concorrência intercapitalista, conjugada pelo progresso técnico e conduzindo ao processo de concentração e centralização do capital, vem acompanhada pela mobilidade - trabalho livre - e controle sobre o trabalho e resume-se, nos dias de hoje, a uma intensa divisão do trabalho.

Ou seja, o desenvolvimento do processo produtivo cria, recria e redimensiona o espaço econômico, suas formas de organização, os postos de trabalho e as atividades disponíveis.

A racionalidade desta relação hegemonizada, econômica, cultural, social, política e institucionalmente, para a acumulação capitalista refuta as teorias do capital humano que resumem as diferenças dos homens como diferenças naturais. O sistema capitalista é visto como sustentado por um verdadeiro aparato institucional que reproduz as relações fundamentais orientadas para o regime de acumulação e para a estabilidade duradoura de um sistema sujeito periodicamente a crises.

Fortalece-se o caráter histórico desta relação social. Como diz Nun:

Sabemos desde Polanyi que o processo de acumulação não é autônomo c nem possui uma lógica própria; por isso necessita de um amplo conjunto de instituições sociais (estruturas políticas e ideológicas incluídas) que o tomem viável. Elas têm a função de assegurar certa estabilidade e previsibilidade a este processo, mediante a regulação tanto da própria competência dos capitais do mercado como dos conflitos entre o capital e o trabalho e entre as distintas frações do capitais. Somente que, como é obvio, a tal regulação dependerá das características e da intensidade que assumam estes conflitos e essa competência, o qual equivale a dizer que é sempre indissociável de uma histórica concreta e que as soluções mudarão segunda as épocas e lugares $(1999,996)$.

O problema da pobreza, por exemplo, tão em voga nos últimos tempos, deixa de ser analisado como um componente residual, uma disfunção do sistema, 
uma carência social que necessita de políticas compensatórias e passa, efetivamente, a ser compreendido como "parte", talvez a pior parte, que compõe e é resultado do modelo dominante de repartição do produto social e das oportunidades.

A partir desta visão histórica-estrutural, importa-nos debater as metamorfoses do mundo do trabalho, o fim do padrão fordista e a proliferação de modalidades de trabalho universalizadas conceitualmente pela controversa denominação de "informais".

\section{A crise da grande fábrica}

A crise de acumulação do modelo taylorista-fordista na década de 70 , período em que o paradigma do assalariamento é superado por uma terceira revolução tecnológica, por métodos enxutos de planejamento e gestão e por um novo período de acumulação, denominado globalização, provoca modificações estruturais que afetam significativamente as formas de representação do capital e do trabalho.

A superação comercial dos limitados mercados nacionais em direção a um mercado global encontra respaldo nas inovações tecnológicas "tele-info-computrônicas",. Estes recursos eliminam distâncias, ao aperfeiçoar a instantaneidade do sistema de comunicação remoto, e possibilitam uma superação quantitativa e qualitativa da produção, que abandona a produção em série e adota o modo de acumulação flexível. Novos materiais e insumos obtidos pela biotecnologia, pela química fina ou novos processos físicos de processamento abrem fronteiras originais para o conhecimento científico e fomentam inauditas possibilidades para a fabricação de mercadorias. Aumenta-se a qualidade final dos produtos, cuja competitividade acontece pela redução de custos, principalmente mão-de-obra. A gestão competitiva e um planejamento otimizado do mercado ampliam o rendimento pela eliminação do desperdício.

Além disso, o fenômeno da financeirização internacional de capital, como padrão sistêmico da organização capitalista, com uma massa de riqueza simbólica sujeita sistematicamente ao jogo de especulações, reduz drasticamente o dinamismo da renda nacional e a taxa de lucro do capital produtivo, ampliando a divisão internacional do trabalho e provocando enormes disparidades na distribuição da riqueza e da sociabilidade.

Se a Revolução Industrial destruiu a empregabilidade rural, a crise da grande fábrica fordista provocou a explosão do setor terciário e a redução brutal de postos de serviços no setor secundário. A classe trabalhadora industrial representa hoje menos de 17\% nos Estados Unidos, 20\% na Grã-Bretanha e entre um 
quarto e um terço nos principais país da Europa Ocidental. A mutação do emprego de produção para os de "colarinho branco ou macacão azul" repercutem no significado do trabalho e na consciência social e coesão dos trabalhadores (Gorz: 1993)

A exigência de especialização no setor de serviços relega à mendicância a mão-de-obra sem qualificação. $\mathrm{O}$ avanço do progresso técnico e os limites de oportunidade de emprego, com grandes evoluções qualitativas e diferenciação do mercado de trabalho, fazem a OIT (1999) afirmar que "as qualificações são cada vez mais decisivas para determinar a empregabilidade de um indivíduo e a competitividade de uma país".

\section{Declínio do trabalho}

Para os trabalhadores serão tão intensas estas transformações de adequação da produção à lógica de expansão de um mercado flexível que promoverá o que Antunes (1996) denomina de "alteração qualitativa na forma do ser do trabalho". O processo de reestruturação produtiva, dominado por uma concorrência predatória, subordina as "relações sociais ao mercado e mercantiliza a vida". (Pochman, 1999:29)

Num (1999) chama a atenção para este trajetória de mudança da importância do trabalho. Até o século XVII, o trabalho, além de não constituir o centro das relações sociais, era identificado como humilhação. O ascenso do capitalismo, a difusão de relações mercantis, a estruturação de mercados e a importância fundamental da mão-de-obra na produção em escala reverteram este quadro. Além disso, a idéia de civilização e a concepção da economia como um domínio autônomo terminaram por configurar o trabalho como a "verdadeira essência do homem". Para Num (1999:992) os economistas deram ao trabalho uma significação homogênea, mercantil e abstrata, cuja essência era o tempo. "A riqueza das nações passou a ser definida como o trabalho de seus habitantes e os meios disponíveis para realizá-lo melhor... O trabalho passou a ser considerado como a mais alta manifestação da liberdade individual e, como mercadoria, emprego. E, como tal, se converteu no fundamento ético - e não apenas económico - do capitalista e a marca por excelência da civilização, em obrigação moral e não unicamente em meio de subsistência".

De onde surge a idéia de que trabalho é a fonte de identidade e da autorealização humanas?" pergunta Victoria Camps (1993:123) ao exemplificar a desimportância do trabalho para os filósofos gregos e a tradição judaica-cristão que expulsa Adão e Eva do Paraíso e, como castigo, os condena a trabalhar e sofrer para ganhar o pão. Para a autora: 
É a industrialização que introduz o trabalho assaalariado, que deixa de ser apenas uma forma de atender às necessidades imediatas, passando fazer parte de um processo anônimo de produção de coisas. Tal processo converte o indivíduo em mera peça de um engrenagem, despojandoo do poder e da vontade de intervir no processo produtivo. $\mathrm{O}$ trabalhador é parte de uma organização regulada de fora, sem nenhum sentido para ele. $\mathrm{O}$ trabalho não vale em absoluto por si mesmo: valido é apenas o salário que se obtém em troca. E um trabalho alienante e inumano: os trabalhadores deixam de pertencer a si próprios, porque são compelidos a vender-se para subsistir.

Para Camps, o trabalho se tornou tão importante, que programá-lo significa estabelecer uma forma de viver em sociedade. O problema agora é o que fazer diante de uma sociedade que não garante mais o trabalho para todos e patrocina deliberadamente a exclusão social. Quais as alternativas possíveis de socialização e construção de uma identidade? Como satisfazer necessidades elementares, normalmente atendidas pela capacidade de venda, po meio do salário, da força de trabalho?

Os reflexos das modificações objetivas na estrutura material da sociedade advindos da reestruturação produtiva fez desintegrar a solidariedade e as obrigações sociais tradicionais. "Exercer uma profissão implicaria um estilo de vida, uma posição na sociedade e uma identidade de grupo distinta, de que era testemunha a associação a um sindicato. Identificar-se com o trabalho significava afirmar uma cultura e uma posição definida". (Gorz, 1993: 27) Hoje, as ocupações são provisórias e os trabalhadores estão condenados a um processo de autodeterminação permanente, buscando sua identidade de forma individualista, fora das relações de trabalho. O imaginário coletivo oriundo da assunção de um determinado papel social, útil e participativo, esvai-se no crescimento do individulismo, como solidão econõmica e social. A mercantilização da sociedade, baseada no fetichismo do dinheiro e no trabalho abstrato, com extração preponderante de mais valia relativa, ameaça os vínculos sociais.

\section{Diversas realidades}

Os impactos destas metamorfoses serão tão distintas quantos às realidades econômicas, sociais e políticas das formações históricas onde elas ocorrem. Os países com forte regulação social, com conquistas oriundas ainda do welfare state, resistem com a manutenção de proteçao, valorização dos contratos de trabalho (mesmo com redução de carga horária) e tratamento compensatório às 
desigualdades que emergirem como exclusão. Outros, como Inglaterra e Estados Unidos, que adotaram o receitual liberal clássico, com amplas liberdades para que o jogo de mercado "acomode" as contradições sociais, com privatização de ativos públicos e flexibilização da legislação de trabalho, o impacto ocorre sob a forma de um assalariamento nivelado por baixo, com direitos precários e extrema vulnerabilidade social. Neste último país, a estagnação do desemprego e os índices de crescimento econômico devem-se seguramente ao uso ampliado da tecnologia, ao papel de credor do mundo e a precarização completa dos empregos.

Verifica-se que a maior parte dos novos empregos gerados nos Estados Unidos e na Inglaterra são de baixa qualidade, refletindo mais uma precarização do postos de trabalho do que uma criação favorável de novas ocupações. Acelera-se a desigualdade social como surgimento de uma subclasse de trabalhadores pobres, com diferenças salariais marcantes entre trabalhadores qualificados e não-qualificados e redução dos salários reais. ${ }^{1}$

Neste cenário, a divisão do trabalho entre os segmentos dinâmicos e periféricos, de baixa produtividade, provoca uma brutal desigualdade na remuneração dos assalariados.

Mesmo na Europa, já se fazem sentir os inconvenientes do desemprego e da informalidade diante de um Estado em depressão fiscal, com perspectivas de colapso nas políticas públicas de proteção social. Os desempregados dos países do G7 (Alemanha, Canadá, EUA, França, Japão, Inglaterra e Itália) passaram de 7,5 milhões de pessoas em 1970 para 21,9 milhões em 1993 e podem chegar a 34 milhões atualmente. Segundo a OIT (1999), cerca de 35 \% da população economicamente ativa do mundo, cerca de 1 bilhão de seres humanos encontram-se em situação de subemprego e desemprego.

Mesmo o Japão, onde o desemprego era indigno para a ascética moral oriental, passa a conviver com esta realidade desagregadora. Nas ex-repúblicas soviéticas, onde o pleno emprego era garantido pelo socialismo burocrático-estatal, a queda do muro significou o desmoronamento do sistema de proteção social e a proliferação em massa do desemprego e da informalidade, inclusive associada à contravenção.

Para a América Latina, a reestruturação produtiva teve um forte catalisador político traduzido pela aplicação do receituário neoliberal conhecido como

${ }^{1}$ Christiane Girard Ferreira Nunes e Analía L. Soria, "Crise Económica e Crise na Cultura do Trabalho", in Sociedade e Estado, n²2, UnB. 1997, p. 256. 
Consenso de Washington. A minimização do estado, através da privatização e redução do gasto público, a estabilidade econômica com combate à inflação e rigidez fiscal, a desregulação dos mercados com papel preponderante para os investimentos privados e uma abertura de economias ao comércio e finanças internacionais alteraram drasticamente o regime social de acumulação vigente.

O que ficou conhecido como a "década perdida" de 80 representou extrema concentração da riqueza com redução dramática de empregos. Segundo a Cepal, a linha de pobreza que atingia $35 \%$ da população em 1980 chegou a $37 \%$ em 1986 e 39\% em 1990. Reduziram-se empregos no setor público, empregos não técnicos do setor urbano formal e cresceram ocupações de baixa produtividade. A expectativa de que os ajustes estruturais frutificassem a partir da década de 90 não se confirmou. Em 1990, o setor formal absorvia 48\% da força de trabalho, em 1996 a proporção desceu a 43\%. De cada 100 novos empregos gerados, 85 corresponderam a atividades informais, de baixa qualidade e sem proteção social. De cada 10 novos postos de trabalho, nove surgiram na atividade de serviços e $90 \%$ deles foram informais.

As reformas introduzidas no setor moderno/formal ern nome da flexibilização levaram a um barateamento do custo da mão-de-obra através da demissão de trabalhadores permanentes e da expansão do número de trabalhadores sem contrato ou com contrato temporário; isto é, mediante uma precarização crescente do emprego também no setor moderno formal. (Nun, 1999:1000)

Para os países do terceiro mundo, reféns todos de um divisão global do capital que lhes condena ao papel de exportadores de divisas, a ausência de capital disponível capaz de dinamizar o mercado interno e o jugo de um receituário monetarista e concentrador, imposto por agências financistas como FMI, BIRD ou Clube de Paris, de acordo com os interesses do FED (banco central norteamericano), determinam uma realidade de estagnação e insuficientes taxas de desenvolvimento capazes de criar oportunidades de trabalho para os jovens que entram no mercado e para os trabalhadores vitimados pela reestruturação produtiva.

Segundo a $\mathrm{CNBB}^{2}$, citando encontro de especialistas na Costa Rica, em $1997,56 \%$ da população latino-americana só podem encontrar ocupação no mercado informal. Dos 17 milhões de empregos criados na América Latina e no Caribe, no período de 1990 a 1995,84\% estão no setor informal, que é responsá-

2 Cartilha da Campanha da Fraternidade 99 "Sem Trabalho, por quê?" 
vel por $50 \%$ do Produto Interno Bruto (PIB) de El Salvador e da Guatemala e por $27 \%$ do PIB da Costa Rica.

A Organização Internacional do Trabalho nos alerta ${ }^{3}$, através do diretor para a América Latina, Victor Tokman, de que cada dez novas vagas que surgem no mercado de trabalho, apenas duas são do setor formal. Ou seja, cerca de $56 \%$ do total de empreendimentos existentes nos centros urbanos da América Latina estão no setor Informal. O Informe sobre El empleo en el mundo (OIT: 1998) cita o caso africano, em que $60 \%$ dos empregos urbanos estão na informalidade. Ilustra também a Bolívia com 57\%, Tanzânia com 56\%, Colômbia com 53\% e a Venezuela-com $46 \%$ de empregos urbanos informais. A Argentina têm apenas um terço da população economicamente ativa com empregos formais, sendo que parte significativa destes com contratos temporários, parciais ou de experiência. Vinte e cinco por cento da PEA estão no mercado informal, 27\% trabalham por conta própria (a maioria sem registros) e 14\% estão desempregada.

\section{E o Brasil?}

No caso brasileiro, o modelo de "desenvolvimento para fora", com substituição das importações, mediante uma dinamização industrial associada a matrizes internacionais, redundou igualmente na concentração econômica e na baixa incorporação de mão-de-obra. A inexistência de uma tradição associativista entre os trabalhadores, que, por meio do sindicalismo, impusesse negociação do marco regulatório, facilitou a consolidação de um mercado de trabalho sob domínio das classes dirigentes, com salários iníquos, alta rotatividade e baixa proteção legal. A inexistência de ruptura política na superação entre o modelo agroexportador e a nova classe industrial-financista-exportadora manteve o caráter conservador da dominação e um Estado privatizado pelas elites.

Economicamente subdesenvolvido e extremamente dependente do fluxo de capitais e da própria transferência de tecnologia, o reflexo da revolução digital, dos novos métodos de gestão e da abertura comercial sobre o mundo do trabalho manifestou-se tardiamente, no final dos anos 80. As incertezas macroeconômicas e a desestruturação do Estado, com perda progressiva da capacidade indutora do desenvolvimento com base no mercado nacional, reduziram o nível de investimentos provocando uma degradação acelerada das condições sociais. Após fracassadas tentativas de contenção do processo inflacionário, da crise da dívida interna/ externa, da estagnação da taxa de produção e da redução do emprego industrial, 
para a visão liberal tornava-se necessário um choque de competitividade capaz de integrar o país no cenário da globalização.

Neste período, através do governo Collor, implementam-se as reformas neoliberais com ruptura de barreiras protecionistas, privatização acelerada de ativos públicos e subordinação do Estado ao papel de fiador da exportação de capitais, por meio do círculo vicioso do endividamento público, interno e externo, que se amplia 'aos galopes'. A profunda heterogeneidade da sociedade brasileira impediu uma reação coletiva, as perversas consequências do "choque" e da recessão do início dos anos 90, agravando a miséria, o desemprego e a violência social. A reação política que destitiu este governo ocorreu por imperativos éticos e não por oposição ao projeto neoliberal.

Com breve intervalo no curto mandato nacional-populista de Itamar Franco é, entretanto, com Fernando Henrique Cardoso que avançam as medidas mais efetivas de reformas estruturais e flexibilização da legislação trabalhista, apresentadas novamente com o objetivo liberal de dinamizar a economia nacional para fora, a partir das necessidades de núcleos dinâmicos exportadores com capacidade competitiva no mercado global. Da mesma forma, o descontrole da dívida pública neste governo, que atinge em 1999 cerca de 50\% do PIB, impede ações eficazes do Estado em políticas públicas que alavanquem o desenvolvimento. Mesmo depois do verdadeiro desmonte da economia nacional, o atual governo persiste com a visão macroeconômica de desenvolvimento (Avança Brasil e PPA200-2003) com base em investimento na infra-estrutura (portos, aeroportos, estradas, energia e telecomunicações) necessária aos corredores de exportação (setores com alguma participação no mercado internacional), e não para a pulverização da renda nacional com dinamização da economia doméstica.

Esta situação, combinada com a recessão imposta pelo controle do crédito e da liquidez monetária, paralisa segmentos inteiros da economia, produzindo demissões em larga escala e fechamento de empreendimentos de larga tradição como as cadeias lojistas Mappin, Mesbla e Lojas Brasileiras, empresas de calçados e têxteis como a Sulfabril e metal-mecânicas como a Cofap. O sistema bancário é internacionalizado, bem como as privatizações dos setores de telecomunicações, elétricos, mineração, ferrovias, siderúrgicas e petroquímicas são abocanhados pelo capital privado externo. A mudança de proprietários, com forte inversão do capital estrangeiro nas nossas empresas (inclusive no setor terciário) e os investimentos em modernização administrativa e tecnológica implica demissões em larga escala nas empresas, situação que também ocorre no serviço público, por uma política de arrocho salarial e redução do aparato estatal às finalidades típicas com terceirização de serviços e privatização de funções. 
Ocorre que a inexistência de uma rede de proteção social e as ralas garantias legais para o mundo do trabalho, que já herdava os paradoxos da convivência entre setores modernos assalariados e outros, com formas precárias, quase escravistas, fez com que o impacto desregulamentador e flexibilizador da legislação proliferasse modalidades informais de trabalho, especialmente desabrigadas de qualquer reconhecimento oficial

TABELA 1. Crescimento do PIB e da produtividade do trabalho na indústria, 1987

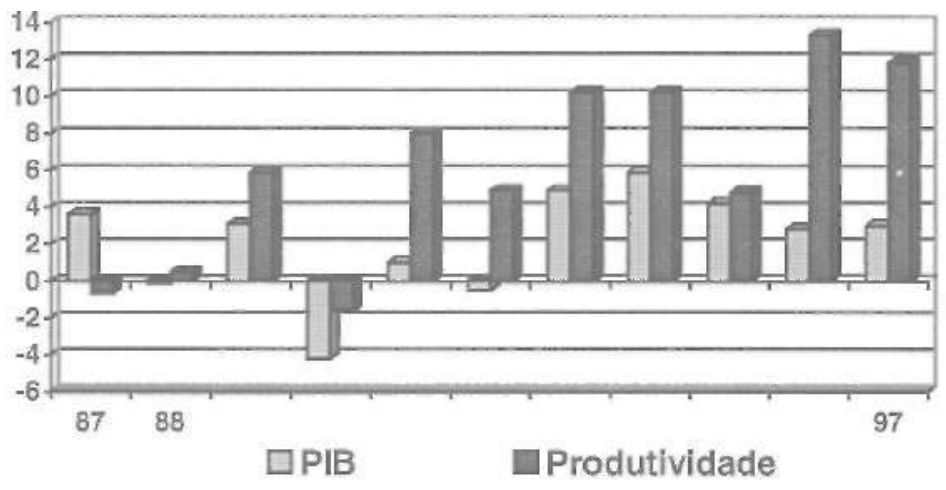

Fonte: IBGE

O choque de competitividade atendeu os objetivos do governo e fez aumentar a produtividade (Tabela 1), mas não foi acompanhado pelo crescimento da taxa de emprego. A manutenção desta produtividade, principalmente, nos pólos dinâmicos da economia, é garantida pela tecnologia e novos métodos de gerenciamento, pelo papel do conhecimento como paradigma produtivo.

Muda, drasticamente e de forma veloz, a composição do emprego (tabela 2). Acaba a importância percentual do emprego agrícola, reduz-se o emprego industrial e cresce o emprego em serviços, comércio e transportes. O processo de subcontratações, por meio da terceirização, prolifera micros e pequenas empresas, trabalhadores autônomos, prestadores de serviços. 


\section{TABELA 2. Taxa de crescimento do emprego por setor da economia, 1992-96 (\%)}

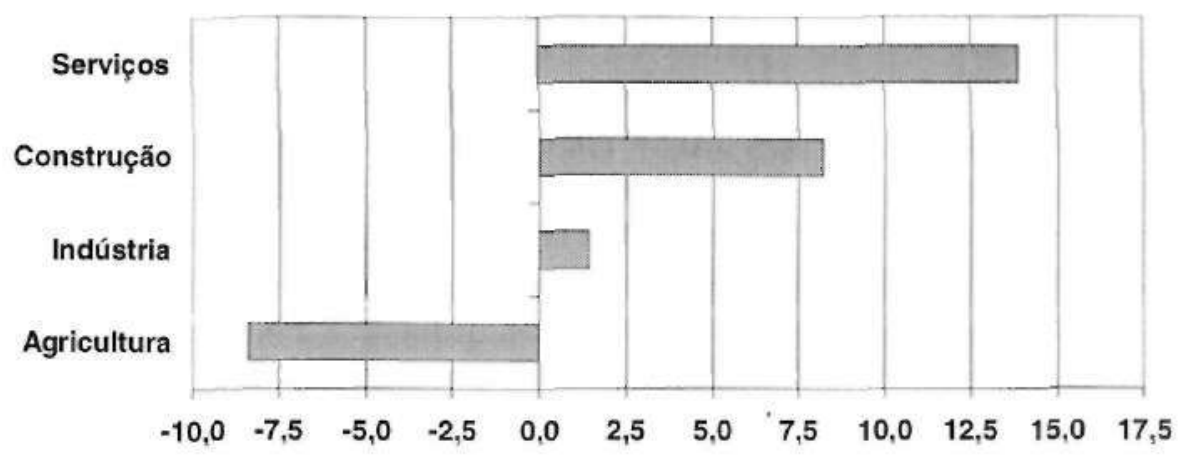

Fonte: PNAD-IBGE

Nossa condição de país periférico, com extrema dependência do fluxo de capitais voláteis e um padrão de crescimento insuficiente para a geração de novas oportunidades, agrava a exclusão do emprego formal e reproduz a informalidade como recurso da maioria. Mattoso (1999: 18) chama a atenção para a redução destas vagas

ao longo dos anos 90 foram queimados cerca de 3,3 milhões de postos de trabalho, sendo que desde que FHC assumiu em 1995 foi contabilizada uma queima nada menos de 1,8 milhão de empregos formais segundo os dados do Cadastro Geral de Empregados e Desempregados (Caged) do Ministério do Trabalho. Até maio de 1999 a indústria de transformação reduziu seus empregos formais na década em cerca de 1,6 milhão (cerca de 73 do que dispunha em 1989), e os subsetores mais atingidos foram os das indústrias têxtil (-364 mil), metalúrgica (-293 mil), mecânica (-214mil), química e produtos farmacêuticos (-204 mil) e material de transporte (-92 mil). A construção civil viu desaparecer cerca de $322 \mathrm{mil} \mathrm{em-}$ pregos formais. O comércio também foi duramente atingido (-294 mil). O setor financeiro reduziu sua mão-de-obra formal em cerca de 354 mil.

TABELA 3. PIB per capita ajustado, 1970-1996 (US\$ PPC)

\begin{tabular}{|c|c|c|c|c|c|}
\hline & 1970 & 1980 & 1991 & 1995 & 1996 \\
\hline Brasil & 2.315 & 4.882 & 5.023 & 5.986 & 6.403 \\
\hline
\end{tabular}

Fonte: PNUD/IPEA/FJP/IBGE - Desenvolvimento Humano no Brasil, 1970-1996 
O histórico do crescimento nominal do PIB (tabela 3) não significa, na prática oportunidade de inserção econômica, muito menos divisão social do produto. A concentração de renda do país, uma das piores do mundo, faz com que, do lado privado, a riqueza gerada se concentre em investimentos financeiros de altos dividendos e poucos riscos e, do lado público, transforme-se em capital alienado às obrigações contratuais do processo de endividamento interno e externo.

Pochman (1999) demonstra que taxa a média de crescimento do Produto Interno Bruto durante o período 1980/89 foi de 2,25\%. O nível nacional de emprego regular e regulamentado registrou taxas média de $1,2 \%$. Para o período de 1990/97, o crescimento do PIB foi de 1,9\% e a taxa de emprego foi negativa em $1,9 \%$. Ou seja, além de os empregos não acompanharem a taxa de crescimento econômico, apresentam-se indicadores negativos.

A quebra dos marcos regulatórios do mercado de trabalho, mediante reformas constitucionais e medidas infra-constitucionais de desregulamentação, agravam os impactos da reestruturação econômica sobre a força produtiva, ampliando situações de precarização e insegurança do trabalhador. As relativas conquistas da CLT e da Constituição de 88 que emblematizavam direitos individuais e coletivos dos trabalhadores estão sendo paulatinamente destruídos pelo argumento liberal de que a flexibilização dos contratos de trabalho e a redução de encargos sociais podem garantir melhores condições de competitividade na globalização. O Brasil entra no século XXI debatendo a miséria, a exclusão social e a apartação, uma retrospectiva triste que remonta a metade do século XIV.

\section{A necessidade do conceito}

De um ponto de vista macroeconómico, a reestruturação produtiva aponta para a concentração económica e a redução do emprego formal. Politicamente, os receituários neoliberais de desregulação e redução do papel do Estado, de abertura comercial sem fronteiras protecionistas, da financeirização produtiva com taxas de juros elevadas e manipulação especulativa da taxa de câmbio atingem em cheio empresas não oligopólicas e concorrências, ampliando a concentração económica e afetando diretamente a qualidade e a quantidade do emprego formal. O crescimento vegetativo da população e os desempregados válidos para uma competição no mercado de trabalho acirram a disputa por uma vaga assalariada e fazem criar um denso espectro de trabalhadores informalizados disputando parcelas do produto social.

Para a OIT (1998), a "lógica da sobrevivência" faz com que a escassez de empregos nas economias dos países em desenvolvimento e os impactos tecno- 
lógicos nas empresas, com concentração em atividades-fins e terceirização das atividades meios, obriga o trabalho em condições precárias, com baixa remuneração, sem registro em carteira profissional e nenhum direito trabalhista.

Neste conjunto de atividades, que variam do "flanelinha" ${ }^{4}$ ao consultor de informática que trabalha em casa por conta própria, temos uma brutal diversidade constitutiva, situação que apresenta obstáculos para uma tranquila definição conceituai.

Mesmo diante da contravérsia entre instituições internacionais ou teses acadêmicas, de infinidade de critérios utilizados ou da impossibilidade de concordarmos com a existência de um suposto "setor informal" apartado da economia formal, é importante e urgente debatermos o que é a informalidade, sua relação com o Estado e se representa uma alternativa de ocupação e integração social que se contraponha ao processo concentrador do modelo industrial, à crescente pauperização urbana, à massificação do subemprego e à disseminação da indigência e mendicância.

O caráter supérfluo do contingente de trabalhadores supranumerário aponta para um permanente risco de fratura (Castel: 1998), com possibilidade de rompimento da coesão social. Por isso, para compreender o significado econômico e social da informalidade, analisaremos quatro correntes que tratam da temática: CEPAL, OIT, a visão liberal e os adeptos da noção de '"informalidade".

\section{O enfoque histórico-estrutural}

É Cacciamali (1983) que destaca enfoques dos marxistas clássicos, que partem da reconstituição do debate sobre exército industrial de reserva e superpopulação relativa e definem o setor informal como

esfera da produção subordinada ao padrão e ao processo de desenvolvimento capitalista, logo, à expansão da produção capitalista a nível nacional e internacional. Tal subordinação se dá em vista de os movimentos da dinâmica capitalista fluírem ao toque das grandes firmas e grupos oligopolistas, que em países economicamente atrasados encontram-se vinculados ao capital estrangeiro e, em geral, ratificados pelos modelos de desenvolvimento fomentados pelo Estado. A subordinação reporta-se tanto na ocupação dos espaços econômicos, no acesso às matérias-primas e equipamentos, na implantação de tecnologia, no acesso a crédito, nas relações de trocas, nos vínculos mais concretos de subcontratação, como esfera da produção ou circulação. A subordinação

Guardador de automóveis em estacionamentos. 
dos movimentos das atividades informais, limitadas aos parâmetros estabelecidos pelas atividades formais, provoca constantemente a destruição e recriação das primeiras.

Esta lógica é retomada no debate sobre a situação da América Latina. A partir do final da segunda guerra mundial inicia-se um amplo debate acerca das alternativas de crescimento dos países periféricos no sentido da ultrapassagem do subdesenvolvimento. As dificuldades do comércio internacional no período de guerra proporcionou o aquecimento de economias nacionais, voltadas que foram momentaneamente para o incremento de um mercado interno. A política de industrialização através da substituição das importações logrou momentos de crescimento econômico e o fortalecimento de setores empresariais nacionais alinhados ou não, às empresas internacionais.

A Comissão Econômica Para a América Latina (CEPAL) nasce de um contexto subsequente a criação de organismos como a ONU e o Banco Mundial e retoma a preocupação com o atraso económico dos países latino-americanos.

A elaboração de projetos de desenvolvimento para estes países é fortemente influenciada por uma visão keynesiana, especialmente no que concerne ao papel central do Estado na condução de políticas de alavancagem económica e implemento da infra-estrutura, tais como energia, transportes e telecomunicações.

O pensamento cepalino do período pode ser resumido pela sequência dos seguintes pontos:

1. a passagem do subdesenvolvimento ao desenvolvimento constitui uma possibilidade real que dependeria da eliminação de alguns obstáculos;

2. o mais importante destes obstáculos residiria na tipo de relação entre o centro (países desenvolvidos) e a periferia; a rigidez do comércio internacional impossibilitava o acesso direto das zonas periféricas ao progresso técnico, necessária para manter os padrões apropriados de crescimento;

3. em consequência, a propagação do progresso técnico dos países centrais para o resto do mundo era relativamente lento e irregular;

4. o acesso dos países subdesenvolvidos às modernas técnicas de produção apenas seria possível com uma ação estatal deliberada para a industrialização, mediante a substituição das importações.

Assim, a Cepal vai privilegiar a ação estatal em favor de um massiva política de industrialização. O Estado, planificador e desenvolvimentista, aparece para este organismo como elemento central da transformação económica e soci- 
al. A industrialização, por seu turno, resolveria por decantação o problema do mercado de trabalho, do emprego e das carências sociais.

A visão centro/periferia, diferentemente da fórmula "países adiantados e atrasados", fortalece as idéias nacionalistas baseadas na perspectiva do desenvolvimento através da industrialização. Mesmo com influências de organismos internacionais, a visão cepalina inaugura um verdadeiro pensamento latino-americano que tem sua sequência com base na teoria da dependência e da marginalidade.

Em oposição às teses cepalinas e dando continuidade a este debate, a "Teoria da Dependência" irá propor, nos anos 60, a noção de desenvolvimentismo baseado na análise dos aspectos estruturais e históricos das formações sociais latino-americanas. A substituição das importações implicaram taxas de crescimento econômico não socializadas através da distribuição de renda e empregos. O novo padrão produtivo, baseado na indústria (em associação ou como filiais de matrizes estrangeiras) e no capital financeiro internacional, liquidou com o paradigma produtivo agroexportador, dominante até o período, e contribuiu para uma forte migração do campo para a cidade. Contrariamente ao ocorrido na Europa no século XIX, na América Latina o processo de industrialização não generalizou relações sociais com base no assalariamento. Pelo contrário, provocou o desemprego, o subemprego, a proliferação do trabalho autónomo e do trabalho nãoassalariado em bolsões urbanos que concentravam a pobreza. A explosão urbana e a falta de oportunidades de emprego provocaram o surgimento de massas marginais, uma superpopulação relativa sem perspectiva de incorporação ao mercado de trabalho formal.

Encarada inicialmente como um problema de estrutura urbana, com a concentração da pobreza nas cidades, a questão da marginalidade social deriva da teoria da dependência e assume que a massa marginal é fruto das relações de produção de uma economia dependente que, em última instância, provoca a coexistência de formas de trabalho tipicamente capitalistas e outras não diretamente integradas.

Abordando esta questão, Lautier (1994) afirma que as atividades exercidas sem regulamentação, tínhamos três registros: marginalidade, sub-emprego e pobreza, com luta pela sobrevivência.

O termo marginalidade foi desenvolvido sobretudo pelos pesquisadores da Cepal. Com base num referencial marxista, denunciavam que os migrantes do campo para a cidade não poderiam ser qualificados de "exército industrial de reserva", em face da impossibilidade estrutural de sua absorção pelo modelo económico da época. Não se tratava de uma superpopulação relativa flutuante, capaz de se incorporar episodicamente ao mercado de trabalho. Configura-se como um 
contingente social desprezível para o núcleo moderno e dinâmico da economia. A noção de marginalidade ou massa marginal era identificada então como setores não integrados à sociedade urbana.

O subemprego emerge da dualidade que dominava o debate sobre a economia do desenvolvimento, entre o setor tradicional, marcado por uma mão-deobra excedente, e um setor moderno. O setor tradicional, representado pelo latifúndio agroexportador deveria liberar pouco a pouco a mão-de-obra rural para as necessidades de expansão industrial urbana. Nos anos 60, este circuito migratório descontrola-se, tendo em vista as modificações do mundo rural, especialmente a perda de mercados internacionais, a redução da renda agrícola e a forte taxa da natalidade no campo. Este, expulsa para a cidade agricultores pauperizados e cria uma massa urbana pobre caracterizada como sub-empregada em face de sua fraca produtividade.

A inexistência de um estado providência obriga setores empobrecidos a uma estratégia de sobrevivência. É uma procura pragmática por condições materiais necessárias à manutenção da vida. Pobreza e estratégia de sobrevivência representam uma terceira abordagem dos anos 60 e 70 que serão retomados pelo Banco Mundial nos anos 80 na discussão de modelos econômicos alternativos.

A partir de 1986, com as políticas de ajustamento estrutural ordenadas pelo FMI e Banco Mundial, o conceito de economia informal passa a ser encarado, além de como uma alternativa econômica, como uma alternativa social capaz de, pela flexibilidade e pouca regulação salarial, criar empregos. Trata-se de um verdadeiro paliativo frente à crise da ocasião, em face de sua capacidade de reintegrar realidades sociais degradadas.

\section{O Relatório Kenya}

O Relatório da OIT sobre Emprego e Renda no Kenya, Africa, em 1972 é reconhecido como importante paradigma para a delimitação conceituai da expressão "setor informal". A OIT considera o setor informal como uma unidade de produção.

A finalidade da conceituação apresentada pelo relatório da OIT era construir uma categoria de análise que descrevesse as atividades geradoras de rendas relativamente baixas e aglutinasse os grupos de trabalhadores mais pobres no meio urbano. A partir de políticas focalizadas, dirigidas a estes grupos e identificadas por metas, poder-se-ia minorar a desigualdades de renda e pobreza ali observadas. O trabalho significou um marco para discussão do conceito justamente pela precisão com que tratou de identificar as atividades e os trabalhadores infor- 
mais, passando a se tornar referência para missões em países africanos, asiáticos, pela Prealc e pelo Banco Mundial (Cacciamali: 1983).

A partir desta consideração, a Prealc, por exemplo, propunha a origem do setor informal ao padrão de desenvolvimento capitalista na América Latina substituição das importações - que gera poucos empregos e, com a explosão demográfica, criava extenso excedente de mão-de-obra que se auto-emprega para sobreviver (Tokman: 1987). A noção de setor informal estava, portanto, delimitada sob a ótica da produção, ou como as pessoas ou as firmas se organizavam, além de sua posição relativa ao conjunto das atividades produtivas.

Ao destacar a idéia de que o setor informal operava em mercados não regulados e constituía uma atividade clandestina, a qual se realizava, principalmente, à margem da lei e em alguns casos, inclusive como contravenção, constituiu para Tokman (1990) um dos fatores mais importantes do trabalho pioneiro sobre este setor, realizado pela OIT.

$\mathrm{O}$ autor demonstra que atualmente a regulação, em geral, assim como a legalidade em particular, converteu-se em ferramentas conceptuais chaves para analisar o setor informal e prescrever soluções.

Para essa mudança de enfoques contribuíram, em primeiro lugar, a concepção do setor informal como resultado da descentralização e reorganização dos processos de produção e trabalho de todo o mundo.

Neste enfoque a existência do setor informal se deriva da busca de flexibilidade e da necessidade de reduzir os custos de mão-de-obra, que o obrigam a operar fora do marco regular. Desta forma se pode ultrapassar as leis e os regulamentos que são onerosos, tanto em termos financeiros como em rigidez. Internamente, a descentralização da produção e seu efeito sobre as formas de trabalho representam um resposta funcional à necessidade de aumentar as margens de utilidade, pois diminuem ou evitam o poder dos sindicatos e permitem que o custo da flutuações da demanda se transfira ao exterior da empresa. Com as novas tecnologias este processo é tecnologicamente possível. (Tokman, 1990)

Por outra parte, a maior competição internacional e a rápida penetração dos países recentemente industrializados nos mercados mundiais tornam necessário reduzir os custos globais da produção. Em consequência, o setor informal - definido como o conjunto de atividades realizadas à margem da regulamentação governamental -converte-se em uma característica universal de dimensões crescentes.

O segundo enfoque, que segue uma linha neoliberal, baseia-se na observação de que, nos países em desenvolvimento as atividades informais se levam a cabo a margem da lei, o que, por sua vez, origina-se em uma inadequada legisla- 
ção e em uma burocracia excessiva e ineficiente. A informalidade e a ilegalidade se convertem, então, em conceitos similares, porém diferentes do enfoque anterior, pois se geram pela impossibilidade de cumprir com o aparato regular existente e não pela necessidade de reduzir os custos e aumentar a flexibilidade. Portanto, esta visão responsabiliza as leis, os procedimentos e o governo de que uma parte importante e crescente do emprego corresponda a trabalhos mal remunerados e de escassa produtividade. Além, sustenta que os regramentos constituem uma barreira para o desenvolvimento das atividades informais, já que somente se pode aceder aos recursos e aos mercados mais dinâmicos por meio de maquinaria legal e institucional vigente. Abordaremos novamente a visão liberal na sequência deste trabalho.

\section{A visão liberal}

Mesmo restrito à análise da realidade peruana, Hernando de Soto (1994) sintetiza em seu trabalho a visão liberal sobre a informalidade. Diferentemente de visões conservadoras que atribuem a massa marginal um problema de disfunção do sistema capitalista, que será resolvida naturalmente pelo crescimento económico, Soto atribui ao setor informal um verdadeiro papel revolucionário, capaz de afrontar velhas estruturas do poder e patrocinar uma nova organização da sociedade e da atividade econômica a partir do pequeno, com a dinamização de uma economia de mercado em um contexto concorrencial.

Critica o que ele chama de Estado mercantilista, ou "economia social de mercado". O Estado, para Soto, não é expressão das coletividades, mas legisla e regulamenta a favor de pequenos grupos de pressão - as coalizões redistributivas - e contra os interesses das grandes maiorias. O Estado, burocratizado e regulamentarista, antepõe a redistribuição, entendida como concessão de privilégios e monopólios a pequenas elites privadas, a produção. Assim, o Estado depende das elites, que dependem do Estado.

Theodoro (1998) critica Soto, por encarar o trabalhador como um miniempreendedor schumpeteriano, numa verdadeira apologia da iniciativa privada. $\mathrm{O}$ trabalhador é sempre visto como um empreendedor capitalista cuja lógica e racionalidade está dirigida para a acumulação. As atividades informais seriam a expressão mais viva do caráter democrático da economia de mercado, uma economia que permanece reprimida em face do intervencionismo estatal e a ação corporativa dos sindicatos.

Para Soto, o Estado do Terceiro Mundo favorece apenas uma minoria privilegiada que não promove o necessário desenvolvimento económico. $\mathrm{O}$ de- 
senvolvimento da economia informal é encarado como tendo uma missão quase insurrecional, de superação das amarras do estado burocrático.

É de se destacar, entretanto, que, apesar da larga percentagem de informalidade na realidade peruana do mercado de trabalho, a maior parte é constituída de empregados, com reduzidíssimos poderes de decisão e, pelo contrário, grande subordinação aos segmentos dominantes. Está provado, também, que a economia informal atinge patamares de acumulação limitados, franjas do mercado formal. A superação destes limites implica a formalização das atividades e na constituição de uma mercado já oligopólico.

\section{Informalidade: uma nova visão}

Recorremos novamente ao trabalho de Theodoro (1998) para discutir as dificuldades metodológicas para o uso do termo "setor informal". Com razão, o autor chama a atenção para o risco da expressão "setor". Incorremos na retomada da lógica dualista proposta pela OIT/Cepal, que trataram de especificar o setor informal com o objetivo explícito de instrumentalizar ações do Estado, por meio de políticas focalizadas para a "massa marginal" .

Há inequívocas inconveniências para uma separação maniqueísta entre um setor formal, estruturado e capitalista, e um setor informal, não estruturado, não regulamentado e com práticas de sobrevivência, sobretudo porque o fenômeno do trabalho informal perpassa até mesmo os setores dinâmicos do capitalismo formal, revelando forte presença em todos os ramos da economia e da sociedade.

Theodoro (1998), com referência em autores como Lautier, Huyette e Morice, propõe o uso do termo "informalidade", uma evolução teórica e política da noção anterior de setor informal. "Informalidade" surge como reflexo de uma relação social, um conceito ligado à lógica de funcionamento da sociedade, à relação completa entre Estado e sociedade, da sociedade em si e suas heterogeneidades. De um plano jurídico, a "informalidade" se caracterizaria pela feição híbrida do não-respeito à lei, engendrando ao mesmo tempo formas mistas de direito (compromissos entre o público e o privado, nos quais o público não está sancionado pelo estamento jurídico formal). Economicamente, a "informalidade" está caracterizada pela não-generalização da relação de assalariamento (o que não garante homogeneidade social) e pela obediência desigual aos parâmetros legais existentes.

Diferentemente dos países centrais, onde existe também atividade informal, nos países do terceiro mundo, esta prática está marcada pela exclusão e não generalização da cidadania. Ao reconhecer a informalidade e mesmo utilizar 
políticas de apoio ao setor, o Estado assume a existência de cidadanias diferenciadas: uns abrigados por uma teia de proteção social (inclusive emprego), outros jogados a própria sorte.

Mesmo considerando as dificuldades analíticas para uniformizar o conceito de informalidade, Theodoro destaca seu uso por inúmeras correntes de opinião. Este uso permite, com maior propriedade, o debate sobre as condições econômicas e sociais do terceiro mundo. Para tanto, o autor acrescenta o conceito de "sistema de emprego", um formulação global, construção teórica que ultrapassa limites econômicos, sociológicos, políticos ou mesmo geográficos. "Sistema de emprego", ao articular as várias estruturas que compõem a heterogeneidade do mercado de trabalho, permite a análise de diferentes domínios, de estudos específicos, tais como a informalidade.

A noção de "sistema de emprego" permite uma aproximação teórica multidisciplinar. Através de uma idéia de rede, articulada e lógica de funcionamento, fica possível uma análise apropriada das atividades económicas, incluindose a questão da "informalidade".

\section{Primeiras observações sobre o conceito}

Esta numerosa divergência sobre a definição de "informalidade" e a evidência empírica de larga magnitude desta relação social no interior das formações capitalistas do terceiro mundo nos provocam para a tentativa de uma abordagem científica deste conceito, em que pesem os inúmeros alertas para a impossibilidade desta empreitada.

O caráter intersticial da manifestação informal, quer objetivamente na forma de exclusão económica e social, quer no interior do mercado formal de trabalho, instiga para aceitarmos as recomendações de Theodoro no sentido de uma aproximação do conceito mediante uma análise histórico-estrutural do modo de produção capitalista e as variações que assume o processo de regulação do mercado de trabalho.

Acreditamos que os paradigmas da terceira revolução tecnológica impõe uma crise de largas proporções ao mundo do trabalho que não se resumem ao fator quantitativo de absorção da força de trabalho ao universo das relações de produção formalizadas. Sobretudo com a globalização, a ampliação dos mercados de consumo e o forte componente da reprodução financeira do capital, com expansão da mais-valia relativa, implicam uma reestruturação económica que amplia significativamente a fabricação de valores, com intensa produtividade, máximo lucro, mínimo desperdício e baixa necessidade de mão-de-obra. Além disso, o 
fenômeno do desemprego estrutural em escala mundial questiona definitivamente o padrão do assalariamento como relação social dominante.

O fim do "trabalho estável e bem remunerado", como diz Nun (1999) suscita o trabalho formal como obrigatoriedade de fomentar rendas necessárias à sobrevivência material. O desenvolvimento de atividades atípicas buscam, com certa criatividade e à revelia da regulação, repartir franjas do produto social. $\mathrm{O}$ trabalho informal vai pragmaticamente moldando novos contornos institucionais para as relações sociais.

O estudo de pesquisas empíricas disponíveis, com mensuração sobre o mercado de trabalho e o trabalho informal, pode nos instrumentalizar para uma abordagem mais esclarecedora acercado conceito de informalidade.

\section{As pesquisas de campo}

Trabalho estatístico realizado pelo IBGE em 50 mil domicílios das áreas urbanas de 753 municípios brasileiros, denominado Pesquisa da Economia Informal Urbana (ECINF) ${ }^{3}$, atesta que 9,478 milhões de empresas atuavam no setor informal em 1997, ocupando mais de 12 milhões de pessoas, entre pequenos empregadores, trabalhadores por conta própria, empregados com e sem carteira assinada e trabalhadores não remunerados.

Este segmento movimentava no mês de outubro daquele ano, R \$ 12,890 bilhões, aproximadamente $8 \%$ do PIB do período.

Para fazer este diagnóstico, o IBGE adotou os critérios da Organização Mundial do Trabalho (OIT), que privilegiam a unidade produtiva sem distinção entre o património pessoal com o capital investido na atividade.

Os critérios estabelecidos pela $15^{\text {a }}$ Conferência de Estatístico do Trabalho da OIT, ocorrida em janeiro de 1993, recomenda cinco considerações fundamentais para análise do setor informal:

1) a delimitação do setor deve ser a unidade económica entendida como unidade de produção, e não o trabalhador individual ou a ocupação por ele exercida;

2) fazem parte do setor as unidades económicas que produzem bens e serviços com o principal objetivo de gerar emprego e rendimento para

Press rclcase do IBGE, "Primeiro retrato completo do setor informal no Brasil" disponível na Internet: www. Ibge.gov.br/scripts/pressrealeses/novopress.asp. O projeto ECINF, de pesquisa do setor informal urbano, iniciou em 1994 com pesquisa exclusivamente no perímetro urbano do Rio de Janeiro. 
as pessoas envolvidas, sendo excluídas aquelas unidades engajadas apenas na produção de bens e serviços para autoconsumo;

3) a produção se caracteriza em pequena escala, baixo nível de organização e pela quase inexistência de separação entre capital e trabalho enquanto fatores de produção;

4) o informal deve se referir ao modo de organização e funcionamento da unidade econômica, e não ao seu status legal ou às relações que mantém com as autoridades públicas. As diversidades de registros, pela ausência de clara base conceituai, não devem se prestar a comparações históricas e internacionais;

5) a definição de unidade económica informal não depende do local onde é desenvolvida, da utilização de ativos fixos, da duração das atividades e do fato de trata-se de atividade principal ou secundária do proprietário da empresa.

Com base nestes pressupostos que identificam o informal como unidade produtiva, incluiu-se na pesquisa do dono de negócio sem ajudantes ao microempresário legalizado com até cinco empregados.

Para facilitar estudos comparativos, foram deliberadamente excluídos o setor agrícola, o emprego doméstico e atividades ilegais, como o contrabando, a prostituição e o narcotráfico.

Primeiramente, seus realizadores concluíram que o segmento não atinge montantes capazes de lhe confirmarem como um "PIB paralelo". Segue tendencialmente se constituindo em um setor "sombra" da economia formal. Com 66\% de empresas não licenciadas pelo estado ou município, o setor não utiliza créditos oficiais (95\%) e mantém baixo índice de investimento nas atividades (apenas 37\% desejam ampliar seus negócios), sendo majoritariamente constituídas por instalações e equipamentos próprios $(73 \%)$. 
TABELA 4. Retrato do setor informal por atividade pesquisa ECINF/IBGE (1999)

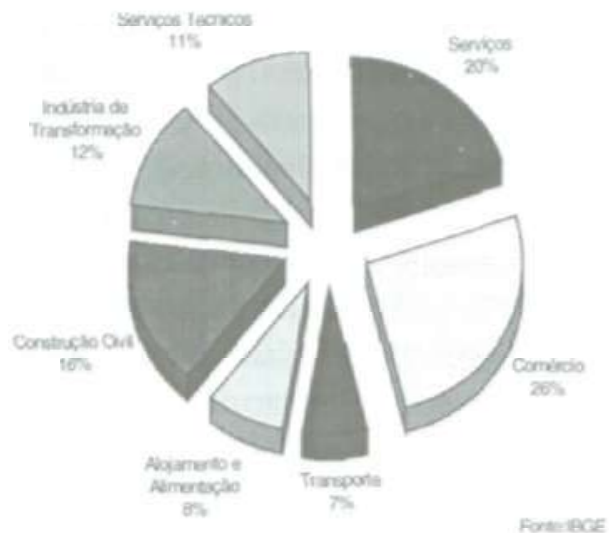

De outra parte, foi confirmada a importância do setor informal para a ocupação de mão-de-obra e sua presença em todos os ramos econômicos (tabela 4). Os trabalhadores pesquisados são preponderantemente por conta própria (67\%), seguindo-se $12 \%$ de empregadores, $10 \%$ de empregados sem carteira assinada, $7 \%$ com carteira e $4 \%$ sem remuneração (dos quais $62 \%$ são de mulheres). Dos donos de empresas do setor informal $74 \%$ possuem até o primeiro grau, $66 \%$ são do sexo masculino e $90 \%$ se dedica exclusivamente a esta atividade.

A renda média mensal é maior para os empregadores $(\mathrm{R} \$ 1.156,00)$ do que para os por conta própria $(\mathrm{R} \$ 457,00)$.

Embora a realização da pesquisa e os dados obtidos sejam de grande significação para a análise do fenómeno da informalidade, é salutar o reconhecimento de que a ausência de atividades caracteristicamente informais e de forte disseminação social, tais como o trabalho rural, doméstico, jogos de azar, narcotráfico e outros, relativiza o dado obtido acerca da participação económica do setor no total do PIB nacional e, por consequência, compromete a magnitude social da realidade constatada.

O setor rural, por exemplo, apresenta uma proporção expressiva de informalidade, motivada pelo intenso uso da mão-de-obra familiar, pela falta de fiscalização das Delegacias de Trabalho e pelo uso abundante de mão-de-obra sazonal, em períodos de plantio e colheita das safras. Os custos para o registro e manutenção de uma carteira de trabalho não compensam a expectativa do trabalho ocupado em tarefas ocasionais ou temporárias. 
Segundo dados do próprio governo federal ${ }^{6}$, existem hoje 4,5 milhões de trabalhadores rurais, o que corresponde a aproximadamente $7 \%$ da população economicamente ativa. Os trabalhadores com carteira assinada correspondem a apenas $29 \%$ do emprego total na agricultura, o que atesta o alto grau de vínculos sem base formal desse setor. No Nordeste, o percentual de pessoas ocupadas na agricultura com carteira assinada baixa para $17 \%$.

É de se destacar, também, trabalho realizado pela professora doutora Francisca Vergínio Soares, da Universidade Cândidos Mendes/Rio de Janeiro, identificando um universo que pode chegar a 400 mil pessoas ocupadas na informalidade do comércio de drogas, apenas no Estado do Rio de Janeiro. ${ }^{7}$ Percebendo o tráfico de drogas como um mercado de trabalho, a autora destaca a importância econômica desta alternativa diante do empobrecimento da população carioca (similar ao papel desempenhado pelo jogo do bicho) e sua tendência de inaugurar novas formas de organização social a partir de opções que incluem até o uso explícito da violência.

A presença e o crescimento de autônomos, também excluídos do ECINF, pode ser diagnosticada pela pesquisa da SEADE/DIEESE, que demonstra a evolução da ocupação total na Grande São Paulo.

TABELA 5. Evolução da ocupação total, emprego formal e informal, trabalhadores autônomos. Grande São Paulo, novembro de 1985-94

\begin{tabular}{|c|c|c|c|c|}
\hline Anos & Ocupados & $\begin{array}{c}\text { Setor privado } \\
\text { Formais }\end{array}$ & $\begin{array}{c}\text { Setor privado } \\
\text { Informais }\end{array}$ & Autônomos \\
\hline 1985 & 103,2 & 103.9 & 104.2 & 100.1 \\
\hline 1986 & 112.0 & 114.1 & 113.2 & 116.3 \\
\hline 1987 & 111,2 & 113,0 & 108.3 & 111,5 \\
\hline 1988 & 115.2 & 118.9 & 120,8 & 116.5 \\
\hline 1989 & 118.7 & 123.1 & 122.8 & 122,2 \\
\hline 1990 & 118,8 & 118.4 & 124,3 & 132,5 \\
\hline 1991 & 124,6 & 114,3 & 141,0 & 149.6 \\
\hline 1992 & 121,4 & 105,5 & 140,4 & 153,0 \\
\hline 1993 & 124,5 & 107,5 & 145,6 & 156,0 \\
\hline 1994 & 127,9 & 111,7 & 171,3 & 159,5 \\
\hline
\end{tabular}

Fonte: SEADE/DIEESE. Novembro, 1994. (média anual de 1985=100)

Mercado de Trabalho Brasileiro. Rumos, desafios e o papel do Ministério do Trabalho. Ministro Eward Amadeo. Câmara dos Deputados, 1998.

Soares, Francisca V. Os trabalhadores do tráfico - uma classe-que-vive-do-trabalho? Mimeo. 
Analisando o quadro anterior (Tabela 5) percebemos que o crescimento da população economicamente ativa (PEA) de São Paulo, no período 1985/94, é acompanhado por uma variação acanhada do setor formal e por um crescimento de perfil ascendente do setor privado informal e do trabalho autônomo. Além do crescimento de 71,5\% do setor informal, importa destacar a evolução dos autônomos em $59,5 \%$ no período considerado.

Para o IBGE $^{8}$, um, em cada quatro trabalhadores das seis capitais estudadas na Pesquisa Mensal de Emprego (PME), é autônomo. São vans utilizadas para vender cachorro-quente, transportar turistas, oficinas mecânicas em garagens, salões de belezas dentro de casa, camelos, vendedoras de bijouterias, quentinhas e toda a sorte de atividades. De 1990 e 1997, o número de autónomos de São Paulo cresceu $50 \%$.

A migração do formal para o informal representou, num primeiro momento, incremento de renda e forte sensação de liberdade da disciplina e rigidez dos padrões fordista do emprego tradicional.

Mesmo os programas de desligamento voluntário animados na esfera pública acenavam as vantajosas condições da autonomia e das perspectivas de ganho económico do livre empreendimento, chegando inclusive a patrocinar programas defranchising, consultorias e outros. Ocorre que apenas para manter vínculos com a previdência social, o trabalhador autónomo terá de desembolsar uma alíquota de $20 \%$ sobre seus rendimentos, um custo que acaba afugentando trabalhadores do registro oficial.

Levantamento do IBGE de 1995 afirma que o Brasil tinha 22,4\% de autónomos, ou cerca de 15,8 milhões de pessoas de um total de 70,7 milhões da população economicamente ativa.

O governo federal, na busca de formalizar empregos e atenuar os dramáticos efeitos do envelhecimento da população (e seus custos de manutenção), acena com um novo pacote previdenciário no sentido de reduzir $9 \%$ a alíquota dos autónomos. Dados da Pesquisa Nacional de Amostra de Domicílios (PNAD) mostram que a Previdência Social cobre apenas $18,6 \%$ do total de 23,8 milhões de trabalhadores do mercado formal e apenas $13,3 \%$ dos trabalhadores autónomos. ${ }^{9}$ Além de reduzir a contribuição dos trabalhadores, o governo também pretende extinguir gradualmente, nos próximos cinco anos, a atual tabela de contribuição dos autónomos, que passarão a contribuir de acordo com a renda auferida.

9 Gazeta Mercantil, 28/08/99 p. A-8. "Menos incentivos para a contratação informal". 
Esta migração desordenada do setor formal para o informal, incluindo-se aqui o autônomo, implicou uma redução significativa de renda, fator verificado pelo Dieese, que encontra certo esgotamento da autonomia como alternativa ao desemprego.

A extrema concorrência por empregos, sem obediência a qualquer marco regulatório, e os efeitos diretos da recessão econômica (perda do poder aquisitivo dos assalariados, falta de liquidez monetária, desestruturação de segmentos inteiros da economia) freiam a tendência de crescimento do poder aquisitivo do setor informal que vinha acontecendo desde o programa de estabilização econômica (46\% de variação do rendimento médio real para o vínculo empregatício 'contaprópria' e $31 \%$ para os 'sem carteira', segundo a PME-IBGE entre 1993/97) e gera uma competição deletéria para o setor.

Mesmo em 1990, ano em que prevaleceu forte recessão económica com início de uma redução percentual do emprego formal até 1992, podemos perceber a tendência de crescimento do setor informal. De 1990 para 1991, os empregos formais, em São Paulo, reduziram 3,9\% e o setor informal privado cresceu 6,7\%.

Da mesma forma, o Mapa do Mercado de Trabalho no Brasil de 1994, também elaborado pelo IBGE e analisando dados de 1990, identificou 48,65\% de informalidade no setor urbano e $82,73 \%$ de trabalhadores informais no setor rural.

Isto significa que em 1990, com uma população economicamente ativa de 62,1 milhões de trabalhadores, apenas 26,2 milhões tinham empregos formais.

Nos dados de PME/IBGE, a fração dos empregos com carteira no total da ocupação caiu de 53,8\% no segundo trimestre de 1991 para 46,9\% no quarto trimestre de 1997. Paralelamente, a parcela do emprego sem carteira e dos autônonomos no total da população ocupada cresceu, respectivamente, de 20,8\% para $24,6 \%$ e de quase $20,0 \%$ para $23,3 \%$, durante o mesmo período. Dessa forma, o conjunto dos informais, tomados pela proporção dos trabalhadores sem carteira e dos por conta-própria no total da ocupação, cresceu de $40,8 \%$ para $47,7 \%$ no mesmo período.

Cabe destacar, na mensuração do problema de desemprego aqui elencado, as diferentes metodologias utilizadas pelos institutos, em especial, IBGE e Seade/Dieese que realizam pesquisas mensais. Enquanto a Pesquisa Mensal de Emprego (PME) realizada pelo Instituto Brasileiro de Geografia e Estatística (IBGE) acompanha o desemprego nas regiões metropolitanas de Recife, Salvador, Belo Horizonte, São Paulo, Rio de Janeiro e Porto Alegre e utiliza como indicador a taxa de desemprego aberto em sete dias, ou seja são considerados desempregados aqueles trabalhadores sem qualquer trabalho e que tenham exercido algum ato de busca de emprego nos sete dias que antecederam a pesquisa. Já o Depar- 
tamento Intersindical de Estística e Estudos Socioeconômicos (Dieese) e da Fundação Seade (Sistema Estadual de Análise de Dados do governo paulista), por meio da Pesquisa de Emprego e Desemprego (PED), investiga o desemprego nos mercados metropolitanos de trabalho em São Paulo, Recife, Brasília, Belo Horizonte, Porto Alegre e Salvador, e tem como principal indicadores a taxa de desemprego aberto em 30 dias, de desemprego oculto pelo trabalho precário (que inclui algum tipo de bico e buscaram emprego) e de desemprego oculto pelo desalento (inclui trabalhadores desempregados e que por motivo de desalento não buscaram emprego no período de referência). As diferenças espelhadas nos gráficos (tabela 6) demonstram a importância de um "meio termo", como diz Dupas (1999), que torne possível uma correta identificação do mercado do trabalho.

Tabela 6. Perfil do desemprego (Taxas médias anuais)

\begin{tabular}{|c|c|c|c|c|c|}
\hline PESQUISA & $\mathbf{1 9 8 9}$ & $\mathbf{1 9 9 4}$ & $\mathbf{1 9 9 8}$ & $\mathbf{1 9 9 9}$ & $\begin{array}{c}\text { Variação em \% } \\
\mathbf{1 9 9 8 / 1 9 9 9}\end{array}$ \\
\hline Total (PED) 1 & $\mathbf{8 , 7}$ & 14.2 & 18,3 & $\mathbf{1 9 , 5}$ & 110,3 \\
\hline Aberto (PME) 2 & $\mathbf{3 . 4}$ & $\mathbf{5 , 1}$ & $\mathbf{7 , 6}$ & $\mathbf{7 . 8}$ & 123,7 \\
\hline
\end{tabular}

Fonte: PME: IBGE PED: SEADE/DIESE

Por último, cabe destacar trabalho realizado pelo Sebrae ${ }^{10}$ de Santa Catarina que analisou 18 bairros de Florianópolis, capital do Estado, diagnosticando as condições da microempresas informais.

O estudo mostrou que o microempresário informal trabalha o ano todo sem direito a férias $(11,97$ meses) para receber um rendimento médio mensal de $\mathrm{R} \$ 760,00$. As principais restrições apontadas são a falta de capital de giro, as dificuldades do mercado e a recessão económica. Cinquenta e um por cento das microempresas atuam na área de serviço (29\% alimentação, $19 \%$ barbearia/salão de beleza e $17 \%$ reparos), $42 \%$ do comércio e $7 \%$ na indústria. Setenta e três por cento ocupa imóveis alugados, $58 \%$ estão funcionando a menos de um ano e $17 \%$, apenas, têm dívidas com bancos ou fornecedores. Noventa e sete por cento vende para consumidores finais, e apenas $3 \%$ para empresas. A pesquisa diagnosticou que $86 \%$ dos microempresários informais desejam legalizar o negócio mas, para tanto, exigem o fim da burocracia e da carga tributária. O baixo capital

${ }^{10}$ Jornal A Notícia, 20/04/1999. Caderno de Economia. 
de giro faz com que $81 \%$ não tenham dívidas, o que significa também baixo índice de investimento no negócio.

Na medida em que o autônomo deixa de ser uma atividade residual e, juntamente com a informalidade, passa a representar uma variável económica dependente de uma parcela diminuta da renda social disponível, temos na prática um processo de seleção, principalmente de serviços e trabalhadores, nivelado pelo menor preço, logo, pelo aviltamento nas condições de sobrevivência.

\section{Conclusão}

Embora considerado por uns como fenómeno "novo"11, típico dos anos 80 , podemos constatar o desenvolvimento de atividades informais desde a consolidação do mercado de trabalho como paradigma de socialização, a partir da revolução industrial, quando se consagra o assalariamento e o próprio trabalho como "suporte privilegiado de inscrição na estrutura social" (Castel 1998: 24). Sua dimensão será proporcional à regulação de cada período considerado e, ao contrário do que pensam os liberais, não se trata de uma estratégia revolucionária empreitada pelo trabalhador contra o Estado, mas, sim, acabou se tornando reflexo de um modelo de acumulação capitalista, que, com a colaboração do Estado, concentra a economia, despreza o trabalho formal e coloca em risco a sociedade salarial, incluindo os mecanismos de coesão e identidade coletivos.

Hoje, com o desemprego estrutural provocado pela reestruturação produtiva do setor formal, o trabalho informal passa a verdadeiramente se constituir numa "estratégia de sobrevivência" para elevado contingente de trabalhadores. A desocupação produtiva formal não é apenas um fenómeno transitório de flutuação da reserva de mercado para as necessidades de expansão da empresa capitalista. Pelo contrário, a economia cresce a taxas tímidas, mas constantes; o capital produtivo é superado pelo capital financeiro; a acumulação produtiva garante sua produtividade com o uso do conhecimento intensivo; os trabalhadores são substituídos por máquinas e processos; a rede de proteção, garantida pelo Estado Social e financiada pelas contribuições do mercado formal, sucumbe pela impotência física de socorrer não o residual, mas a maioria excluída; o trabalho formal progressivamente vira privilégio de uma minoria, e a precarização e a informalidade condena a maioria a ocupações precárias de sobrevivência.

${ }^{11}$ Paul Singer, Globalização e desemprego, diagnóstico e alternativas. São Paulo: Editora Contexto, 1995. 
Este cenário de metamorfoses do trabalho e perda crescente de sua dimensão formal, incitam-nos ao debate teórico sobre o que é, afinal, o trabalho informal. Se, nas formações do terceiro mundo, esta manifestação já desponta como prática social majoritária podemos concluir que sua existência não confronta revolucionariamente o Estado, mas, sim, mantém uma relação de dependência e subordinação intrínseca ao modo de produção capitalista, desenvolvendo-se em toda a extensão do tecido social. Esta associação talvez seja o motivo pelo qual a ameaça de coesão social seja apenas latente.

A resposta simplória que opta pelo maniqueísmo de que é informal o que não é legal, não nos satisfaz. Entender esta nova faceta econômica e social da sobrevivência humana, dado indicadores que apontam seu crescimento e perenidade, poderá revelar uma nova tendência para a sociabilidade do novo século.

O conceito do que definimos como "informalidade" passa evidentemente pelo "corte" sociológico do objeto investigado, em nosso caso, uma sociedade absolutamente heterogênea, que faz das diferenças internas motivo de frágil coesão social e reprodução económica com indisfarçável desigualdade. Esta situação aponta para uma sociedade dividida, com direitos e deveres assimétricos, definidos pela concentração económica e de oportunidades. A parte "rica" da sociedade concentra a riqueza, detém os empregos formais e hegemoniza o Estado, logo usufrui proteção social que deveria privilegiar os mais necessitados. Ocorre que o Estado sucumbe à crise fiscal e às políticas liberais: fragiliza-se, diminui de tamanho e inserção, arrecada menos e aumenta compromissos, tais como segurança, saúde, educação, previdência e assistência social. Logo, o contexto Estado-sociedade é de uma crise anunciada.

Mesmo que não tenha sido a preocupação central deste trabalho, cabe destacar, sucintamente, o papel da informalidade como instituinte de representações sociais. Apesar do seu alto grau de insegurança e aleatoríedade, o trabalho informal inaugura formas alternativas de sociabilidade. Os mecanismos de entrada e permanência, o reconhecimento e a utilidade social de várias das atividades, bem como mesmo os necessários intercâmbios com os segmentos formais, ensejam um manancial de códigos e simbolismos, de ampla aceitação pública, que relativizam a marginalidade social de um conjunto representativo de trabalhos informais.

A diversidade deste objeto, como já verificamos, sugere, entretanto, a impossibilidade de um conceito fechado sobre a informalidade. Impõe-se uma visão aberta, sistmica, generalizante, que apreenda o caráter intersticial da atividade e seus reflexos para as instituições sociais.

O estudo da economia e do trabalho informal, a desmistificação de um suposto caráter subterrâneo, marginal, conspirativo à institucionalidade, além da 
revelação de sua participação intrínseca e subordinada ao modelo dominante, oriundo da etapa de acumulação emblematizada pela globalização e terceira revolução industrial, é fundamental para uma reflexão contemporânea sobre a condição humana, suas perspectivas de reprodução material e social.

\section{Bibliografia}

ANTUNES, R. "A centralidade do trabalho hoje" in Sociedade e Estado. Volume XI. Brasília: Universidade de Brasília, 1996

Adeus ao trabalho ? Ensaio sobre as metamorfoses e a centralidade do mundo do trabalho. São Paulo: Editora Cortez/UNICAMP, 1995.

CACCIAMALI, M. C. Setor informal urbano e formas de participação na produção. São Paulo: IPEUSP, 1983.

CAMPS, V. "O sentido do trabalho e o ethos individualista" in Revista O socialismo do Futuro $\mathrm{n}^{\circ}$ 6, Instituto Pensar-Fundação Sistema, 1993.

CASTEL, R. As metamorfoses da questão social - uma crónica do salário, Petrópolis: Vozes, 1998.

CNBB. "Sem Trabalho, por quê?", Texto Base da Campanha da Fraternidade. São Paulo: Editora Salesiana Dom Bosco, 1999.

DE SOTO, H. Economia Subterrânea. Uma análise da Realidade Peruana. Rio de Janeiro: Editora Globo, 1986.

DE SOUZA, P. R. Emprego, salários e pobreza. São Paulo, Hucitec, 1980.

DREIFUSS, R. A. A época das perplexidades. Rio de Janeiro. Editora Vozes, 1996. DUPAS, G. Economia Global e Exclusão Social. São Paulo: Paz e Terra, 1999.

Folha de São Paulo, "Emprego informal chega a 56\% na AL", de 10/07/97.

Folha de São Paulo, "O Rodízio de Nossos Empregos", Miguel Jorge, Caderno Dinheiro, de 17/03/99.

Folha de São Paulo, Caderno Dinheiro "Crise Ameaça até o trabalho informal", de 21/03/99.

GORENDER, J. "Globalização, Tecnologia e relações de trabalho". São Paulo: Instituto de Estudos Avançados - USP, 1996.

GORZ, A. "O declínio da relevância do trabalho e a ascensão de valores póseconômicos" in $O$ socialismo do futuro, futuro do trabalho, Revista $\mathrm{n}^{\circ} 6$. Instituto Pensar - Fundação Sistema, 1993.

HANN, H. "El Sector Informal en Centroamerica". Programa Mundial del Empleo (PREALC). Investigaciones sobre Empleo n 27; Genebra, OIT, 1990.

HART, K. "Informal income opportunities and urban employment in Ghana", presente à la confèrence sur le sous-emploi urbain en Afrique et publié dans le Journal of 
Modem African Studies. Institute of. Development Studies, University of Sussex, II, 1, 1973.

HOLZMANN DA SILVA, Lorena. "Divisão social do trabalho" in Trabalho e tecnologia, (org.) Antônio David Cattani, Porto Alegre: Vozes, 1997.

LAUTIER, B. L"économie informelle dans le tiers monde. La Decouverte, 1994. . "Representação e regulação do Estado na América latina". Revista de Sociologia. Brasília: Universidade de Brasília, 1999.

MATTOSO, J. O Brasil desempregado; como foraa destruídos mais de 3 milhões de empregos nos anos 90. São Paulo: Editora Fundação Perseu Abramo, 1999.

MESA-LAGO, C. "La Scguridad social y El sector informal". Programa Mundial del Empleo (PREALC). Investigaciones sobre Empleo $\mathrm{n}^{\circ}$ 32. Organização Internacional dei Trabajo, 1990.

MEZZERA, J. e VEJA-RUIZ M. L. "Trabajadores vulnerables y sector informal: de lo económico y lo normativo". Oficina Internacional dei Trabajo. Organização Internacional de Trabajo, 1995.

NUM, J. "El futuro del empleo y la tesis de la masa marginal" in Desarrollo Económico, Revista de Ciências Sociales, $\mathrm{n}^{\circ}$ 152, Instituto de Desarrollo Económico e Social. Buenos Aires, 1999.

OIT. El Dilema del Sector no Estructurado, Memória del Director General. $78^{\circ}$ Reunião da Conferência Internacional del Trabajo. Genebra, 1991.

OIT; Informe sobre El Empreo en El Mundo 1998-1999. Empleabilidad y Mundializacion - papel fundamental de la formacion (Prensa). Oficina Internacional del Trabajo. Genebra, 1998.

POCHMANN, M. O trabalho sob Eogo Cruzado. São Paulo: Contexto, 1999.

RIFKIN, J. O fim dos empregos: o declínio inevitáveis dos níveis dos empregos e a redução da força de trabalho. São Paulo: Makron Books, 1995.

SINGER, P. Globalização e Desemprego. São Paulo: Editora Contexto, 1998.

THEODORO, M. L. Vintervention étatique sur l'informei au Brésil. Thèse de docteur de 1'Université Paris-L. Directeur: Bruno Lautier. Paris: mimeo, 1998.

TO KM AN, V. E. "El sector informal quinze anos despues". Documento de Trabajo 316. Santiago do Chile: OIT/PREALC, 1987.

"Mas alla de la regulacional". El sector informal en America Latina. Santiago do Chile: OIT/PREALC, 1990. 


\section{RESUMO}

Os autores analisam as modificações do mundo do trabalho a partir da crise do modelo fordista no final dos "trinta gloriosos" anos do pósguerra. O uso intensivo de tecnologia, a abertura de mercados globalizados, a financeirização do capital e as modernas técnicas de gestão e planejamento do novo modo de acumulação flexível alteram a composição, a qualidade e a quantidade do emprego colocando em risco o assalariamento formal como paradigma social. A flexibilidade e a precarização dos contratos disseminam modalidades informais de trabalho, como recurso de sobrevivência para uma parcela não residual de trabalhadores. São debatidos os conceitos de "setor informal", as várias correntes que abordam o fenômeno da informalidade nos países de terceiro mundo e pesquisas de campo já realizadas sobre o segmento. Na conclusão afirmam a importância do trabalho informal para a geração de renda, empregos e para a manutenção da coesão social, principalmente em face de sua existência subordinada intersticialmente ao modo de acumulação dominante.

Palavras-chave: Trabalho informal, flexibilização, precarização, regulação, assalariamento, globalização, coesão social, modo de produção, metamorfoses do trabalho, proteção social, marginalidade, informalidade, setor informal. 